\title{
Enunciación
}

http://revistas.udistrital.edu.co/ojs/index.php/enunc

DOI: http://dx.doi.org/10.14483/udistrital.jour.enunc.2014.2.a15

enunciación

RESEÑA

\section{Segundo Encuentro Nacional de la Red Iberoamericana de Estudios de la Oralidad}

\author{
Bogotá D.C. (Colombia) 10 de octubre de 2014 \\ Universidad de La Salle y Universidad Distrital Francisco José de Caldas \\ Mirta Yolima Gutiérrez Ríos ${ }^{1}$
}

Para citar este artículo: Gutiérrez, M. Y. (2014). Segundo Encuentro Nacional de la Red Iberoamericana de Estudios de la Oralidad. Enunciación, 19(2), 377-379.

El Segundo Encuentro Nacional de la Red Iberoamericana de Estudios de la Oralidad, realizado en Bogotá el 10 de octubre de 2014, por los grupos de investigación Educación y Sociedad de la Universidad de La Salle y Lenguaje, Cultura e Identidad de la Universidad Distrital Francisco José de Caldas, contó con la participación de 110 miembros del Nodo Colombia, lo cual constituyó un nuevo paso hacia la consolidación de la Red Iberoamericana de estudios de la oralidad conformada por investigadores y académicos de varios países de habla hispana.

El objetivo principal de este y los demás encuentros promovidos por la Red ha sido reconocer los avances logrados en torno a los estudios sobre oralidad, con el ánimo de contribuir a la constitución de espacios interinstitucionales de encuentro que favorezcan la construcción y el intercambio de saberes, líneas de investigación, proyectos y experiencias derivadas de los distintos campos disciplinares en los que se estudia la oralidad.

Esta vez se quiso profundizar en el carácter interdisciplinar de la oralidad a nivel teórico y práctico. Para ello, se optó por la dinámica del panel con el propósito de reunir a varios académicos e investigadores en torno a dos temas concretos: ${ }^{2}$

Panel 1: Contribución de las disciplinas a la investigación de la oralidad.

Panel 2: Experiencias de investigación, problemas y perspectivas de análisis de la oralidad.

Esta convergencia posibilitó poner en escena distintos enfoques, campos disciplinares y diferentes puntos de vista. El panel 1, por ejemplo, se caracterizó por abordar el decir-hacer en los sistemas religiosos de inspiración afro en Colombia, allí Luis Carlos Castro Ramírez del grupo G Caribe, planteó algunas prácticas rituales del quehacer religioso, representadas en mitos, plegarias y cantos de tipo oral que evidencian cómo la palabra oral tiene un carácter enunciativo o de acción. Dicho estudio se complementa con el realizado por Adriana María Valera Rolón, del mismo grupo de investigación, quien analizó cómo en las letras de canciones de música cubana hay un complejo sentido mágico-religioso de la santería, y viceversa.

1 Presidenta de la Red iberoamericana de estudios sobre la oralidad. Correo electrónico: mygutierrez@unisalle.edu.co

2 El panel como una forma de exposición oral de carácter académico surgió en el año 1929, lo propuso Harry Overstreet en la Universidad de Berkley, California 
En este mismo sentido, Eduardo Antonio Silva, también del grupo G Caribe, presentó una búsqueda sobre la oralidad en el creole sanandresano y las diversas estrategias para desestabilizar la imposición eurocéntrica de una historia oficial y sus modos de producción archivística. Finalmente, Éder García-Dussán del grupo Lenguaje, Cultura e Identidad, cerró este panel con una reflexión sobre los problemas de voz del profesor y cómo esta tiende a patologizarse hasta hacer parte del malestar docente.

Es importante señalar que las investigaciones mencionadas anteriormente se inscriben en el eje antropológico y sociocultural de la oralidad. Sin duda, subyace una variedad de temas, problemas y líneas de investigación que enriquecen esta línea de la Red; no obstante, se advierte la necesidad de un mayor desarrollo epistemológico de la oralidad desde los presupuestos disciplinares que sustentan cada investigación. Es muy importante centrar la reflexión en los matices, formas de dinamización y teorización de la oralidad.

El panel 2, centrado en experiencias de investigación, problemas y perspectivas de análisis de la oralidad, dio cuenta de trabajos desarrollados en contextos escolares. Por ejemplo, Giovanny Castañeda, doctorando de la Universidad Distrital Francisco José de Caldas, presentó avances de un estudio sobre maltrato físico, verbal, emocional y simbólico en las interacciones entre profesores y estudiantes. Magnolia Sanabria Rojas del grupo de investigación Merawi. Subjetividades, saberes y territorios, expuso los logros en cuanto a la producción de comunicación oral auténtica y autogenerada en la enseñanza del Español como segunda lengua en un resguardo indígena Sikuani y en un colegio oficial de Bogotá.

Por su parte, Genith Mercedes Solís del grupo de investigación Binta Zakiya, mostró cómo ha logrado recuperar el papel de la oralidad mediante talleres con estudiantes de seis instituciones educativas del municipio de Tumaco, desde diferentes manifestaciones de la cultura: música, danza, pintura, radio, televisión, teatro, poética y cuentería.
También Constanza Olaya Rondón del grupo de investigación Ágora, expuso sus avances en cuanto al desarrollo de la argumentación oral en niños de Básica Primaria. Cerró este panel Carolina Arévalo Rodríguez del grupo de investigación Educación, pedagogía y subjetividades de la Universidad de La Salle, con una interesante experiencia sobre didácticas del discurso académico oral en la Educación Superior.

Dichas experiencias investigativas, inscritas todas en el eje pedagógico y educativo de la oralidad, evidenciaron una vez más el interés de los docentes investigadores por reemplazar la enseñanza esporádica de la oralidad por una práctica continua, reflexiva, sistemática y articulada con la didáctica de la escritura; de tal forma que posibilite a los profesores ayudar a construir un saber-hacer relacionado con el uso social de la oralidad en diversos contextos y niveles de complejidad y, a los estudiantes, a lograr mayores niveles en su capacidad de hablar y escuchar, reflejada en la apropiación crítica de discursos, la construcción colectiva de aprendizajes y la participación en la negociación de sentidos, es decir, mejorar su competencia discursiva oral.

Ahora bien, las conferencias centrales de la mañana y la tarde se inscribieron en el eje de la literatura y la oralidad. En la mañana, la profesora Mónica Del Valle de la Universidad de La Salle, abrió el encuentro con una conferencia magistral titulada: Máscaras acústicas: los rumores del mundo. Allí planteó cómo se ha venido pensando la oralidad en los estudios literarios de Colombia y Latinoamérica. Inició presentando una relación de los escritores con lo oral, luego realizó una mirada crítica a algunos enfoques que se han empleado para el estudio de la oralidad en la literatura y finalizó con el análisis de algunas producciones literarias del Gran Caribe para advertir sus bordes disciplinarios y su riqueza cultural.

En la tarde, el profesor y escritor Hugo Niño, jubilado de la Universidad Distrital, cerró el encuentro con la conferencia titulada: La vOz y la letra: marcas en litigio. Su planteamiento se centró en 
cómo la escritura ha transformado las estructuras sociales y ha impulsado poderes hegemónicos y experimentos globalizantes y cómo la palabra oral ha perdido su valor axiológico y su alcance práctico. Se trata de un litigio que ha desencadenados una serie de antinomias sociales: salvajismo/civilización, razón/inconsistencia, pensamiento simultáneo/pensamiento lineal.

Al cierre se realizó el lanzamiento del tercer libro resultado de los avances investigativos de los miembros de la Red iberoamericana de estudios sobre oralidad, auspiciado por la Editorial de la Universidad Distrital Francisco José de Caldas.

El libro: Oralidades. Saberes y Experiencias de investigación en Red hace parte de la Colección Diálogos y fue editado por Raquel Pinilla y María Elvira Rodríguez, del grupo de Lenguaje, Cultura e Identidad. La obra contiene trabajos de diecinueve autores asistentes al II Congreso Iberoamericano de Oralidad realizado en el año 2013 en la Universidad de Granada. Sus textos respondieron a tres tipos de espacios de participación: conferencias, mesas redondas y comunicaciones, que expresan la pluralidad de perspectivas investigativas desde las cuales es posible abordar los problemas de la oralidad en los ejes propuestos por la Red. La publicación, con prólogo de Pilar Núñez Delgado, indica los avances alcanzados en países como España, México y Colombia y, particularmente, resalta el papel que ha cumplido la Universidad Distrital en el apoyo a los proyectos de investigación, organización y vinculación de sus docentes a eventos y la divulgación de resultados relativos a este campo de estudios.

Finalmente, cada encuentro convoca a uno nuevo, el siguiente será en México D.F. en octubre de 2015. Cabe señalar que hace tres años, en junio de 2011, cuando nació esta Red en el marco del primer encuentro iberoamericano impulsado por tres grupos de investigación de Colombia, México y España, soñábamos con lograr convocar un movimiento de profesionales-investigadores organizado en varios nodos nacionales y regionales de la geografía mundial y hoy somos testigos de cómo se ha ido realizando este sueño, de manera excepcional, gracias a la decisión de todos los interesados en consolidar comunidades de conocimiento y de práctica de la oralidad. 